\begin{tabular}{lc}
\hline UAD & ADJES (Ahmad Dahlan Journal of English Studies) \\
VOL 8, No. 1,1-16 \\
$\begin{array}{l}\text { Universitas } \\
\text { Ahmad Dahlan }\end{array}$ \\
https://doi.org/10.26555/adjes.v8i1.17446
\end{tabular}

\title{
Cohesive Devices in English Contents Written by Blog Writers and English Department Students
}

\author{
Gullit T. Taufan \\ Email: gullittaufan@polije.ac.id \\ Politeknik Negeri Jember, Indonesia
}

ARTICLE INFO

Article history

Received: 25 July 2020

Revised: 12 November 2020

Accepted: 15 March 2021

Keywords

cohesive devices

English blog contents

Indonesian blog writers

English department students

\section{ABSTRACT}

This study was conducted to investigate the use of cohesive devices in English writings written by Indonesian blog writers and English department students. It also focused on investigating the appropriateness of the use of cohesive devices in the writings. The data were English texts written by 15 blog writers and 15 English department students and analyzed manually by employing content analysis. The findings show that (1) lexical cohesion was used most frequently by both groups of the study followed by reference, connectives, and substitution and (2) the blog writers were more capable in using the cohesive devices appropriately in their writings.

This is an open access article under the CC-BY-SA license.

\section{Introduction}

Cohesion is an essential aspect to take into consideration when investigating text quality because it can be regarded as a powerful tool in discourse production and interpretation (Tanskanen, 2006: 27) from which the texture or the property of 'being a text' that distinguishes a text from non-text can be created (Halliday \& Hasan, 1976: 2). For sure, when investigating text quality, the cohesion belongs to one from various aspects i.e. vocabulary, morphology, phonology, and syntax (Saville-Troike, 2006: 150-151). This means that relying on the cohesion as a single aspect to conclude the quality of certain texts is not acceptable. This is also the reason why the debates about how powerful the cohesion is in creating unified text do exist (see Tanskanen, 2006). However, there is no doubt that cohesion is essential to study because the cohesion creates relations of meaning that exist within text and define it as a text (Halliday \& Hasan, 1976: 4).

Halliday and Hasan (1976: 4) explain that cohesion can be created when the elements in a text is dependent on one another which means that one element presupposes the others to set up the relations of the elements to be integrated into a text. In this case, the cohesion can be 
expressed grammatically i.e. reference, substitution, and ellipsis, and lexically, and through the use of connectives that belong to the type on the borderline between the two types (Halliday \& Hasan, 1976: 5-6). Totally, there are four types proposed i.e. reference, substitution, ellipsis, connectives, and lexical cohesion.

Reference, according to Halliday and Hasan (1976: 31), is a type of cohesion with specific nature of the information that is signaled for retrieval. Reference provides directive indicator that information is to be retrieved from elsewhere. Halliday and Hasan (1976) classify reference into two: endophoric and exophoric. The endophoric reference can be divided into anaphora and cataphora. As implied, endophoric reference can be regarded as textual cohesion as it exists to connect different elements explicitly within discourse while the exophoric reference is applied to build potential relationship between the text and its readers. Because the exophora builds the references to the "shared world" outside the text, it is not necessarily regarded as cohesive device (Halliday \& Hasan, 1976: 18).

Other types of cohesive relation that belong to the grammatical cohesion are substitution and ellipsis. Substitution, unlike the reference, creates a relation between text elements in the wording rather than meaning and functions as the replacement of one item by another (Halliday \& Hasan, 1976: 88). The ellipsis, like the substitution, contributes to text relations. However, it is considered as 'substitution by zero' because the presupposed item is replaced by nothing (Halliday \& Hasan 1976: 144).

Halliday and Hasan (1976: 274) explain that different from the previously elaborated grammatical cohesion, the lexical cohesion creates texture that is achieved by the selection of vocabulary including reiteration that involves repetition of a lexical item, general world, and synonym, near-synonym, or superordinate (Halliday \& Hasan, 1976: 278).

The last type of cohesive relation is conjunction. According to Halliday and Hasan (1976: 226), conjunction is different from other types of cohesive relations as it is not simply an anaphoric relation like what reference, ellipsis, and substitution perform. Conjunction provides the elements to create cohesion indirectly by virtue of specific meanings. Conjunctive elements express meanings that presuppose the presence of other components in the text. Regarding the types of conjunction, Halliday and Hasan (1976: 238) adopt a scheme that consists of four categories: additive, adversative, causal, and temporal.

Many studies with the current topic focused on the countries where English is considered as a foreign language with the emphasis to investigate how the L2 learners or speakers deal with the cohesive devices when they had to compose English texts. Some of the research focused on the use of all types of cohesive devices: grammatical, lexical, and connectives (Castro, 2004; Chanyoo, 2018; Nindya \& Widiati, 2020; Rahman, 2013; Warna et al., 2019), while some focused 
specifically on the lexical cohesion (Jaya \& Marto, 2019; Kafes, 2012; Mirzapour \& Ahmadi, 2011; Wang \& Zhang, 2019) and grammatical cohesion (Alarcon \& Morales, 2011; Othman, 2019; Trisnaningrum et al., 2019).

Rahman's (2013) study on the cohesive devices used by Omani L1 Arabic student-teachers shows that the repetition, as a subtype of lexical cohesion, appeared to be the most frequently used by the 1st-year and 3rd-year L1 Arabic student-teachers. This is in line with Chen (2008) who finds that that the subjects, in this case EFL students at Tsing Hua University, used repetition very frequently with the percentage of $70 \%$ compared with the uses of synonyms (11\%) and collocations (10\%), while antonyms and superordinates were relatively less used. Jaya \& Marto (2019) also find that repetition is used by English Language Education students at Madako University with the percentage of $93 \%$ followed by synonym, collocation, and superordinate. Other studies conducted by Castro (2004), NaYoonHee (2011), Mirzapour and Ahmadi (2011), Kafes (2012), Zoltán (2013) showed the similar conclusion.

Another interesting fact found by the Rahman (2013) is that the subjects' proficiency did not show significant difference in their use of cohesive devices. Even the students who have completed the foundation year and several courses in writing and discourse during the five semesters of study might not sufficiently skillful in utilizing cohesive devices in their English compositions. At this point, considering other aspects such as individuals' specific interest should be essential because this might potentially influence the writing quality. For instance, Prijambodo who conducted and case study to investigate the successful Indonesian writer named Budi Darma (2009) found that the subject had special interest in writing influenced by his hobby in reading English texts.

In addition, it is also found that the cohesive devices density within a text does not significantly and positively influence the quality of the text (Zoltán, 2013). It means that even a text with enormous uses of cohesive devices cannot be considered as a well-constructed piece. The lack of comprehension, knowledge, and ability in writing more likely leads to the inappropriate use of cohesive devices (Trisnaningrum et al., 2019).

There is no doubt that the different studies conducted previously have led to important empirical data. Most of the studies focused on investigating the use of cohesive devices performed by learners either high school or undergraduate students. At this point, considering other areas to investigate the cohesive devices used by different research subjects like English blog writers should be interesting.

English blog writers are individuals who write English contents for websites owned and/or managed by individuals who, mostly, focus on earning money from the virtual world. To attract visitors to visit the websites, they need to deal with a complex method called Search Engine 
Optimization (SEO) with the main purpose of achieving the position on the first page of Google search engine (Webmaster Tool Help - Search Engine Optimization / SEO). The blog writers always have the position to contribute to the websites by providing high quality and unique blog contents as an important aspect in SEO. Today's trend strongly suggests that the blog contents have to provide value or engage blog visitors (Hubspot, 2014; Clark, 2014; Tutorials Point, 2015). In short, the contents should not only be intended to enable search engine bots to digest them fast and easily in order to make the web-pages are indexed quickly and to promote the blogs to the higher ranks but also meet the quality expected by the users.

Conducting research on the use of cohesive devices in English blog contents by Indonesian blog writers is important because the previous studies related to the cohesion and cohesive devices do not, yet, touch this relatively new field and the research will be beneficial to describe the current quality of Indonesian blog writers in writing English blog contents.

Accordingly, the current study was aimed to investigate (1) the cohesive devices used in English blog contents written by Indonesian blog writers and (2) English department students as well as (3) the extent to which blog writers differ from English department students in using the cohesive devices in their writings, specifically in terms of appropriateness.

\section{Method}

This study employed qualitative research method specifically content analysis research design which is widely used in educational research (Ary et al., 2010: 457; Freankel \& Wallen, 2006: 484) and applied to written or visual materials for the purpose to identify specified characteristics of the material (Ary et al., 2010: 457). The contents analyzed were English writings written by Indonesian blog writers and English department students.

There were two groups of research subjects involved in this study i.e. Indonesian blog writers and English department students. The blog writers were 15 individuals who were joining an Indonesian blogging forum called Ads.id. They were mostly graduated from undergraduate programs majoring in English, either English education or literature, who worked as freelance blog writers. The second group consisted of 15 students who had finished most of the undergraduate courses including the writing classes. The required writing topic was "Home Improvement" written in 300- to 400 -word long. The topic was chosen because it was a popular niche in blogging.

To gain the data from the blog writers, the forum of Ads.id was visited in order to collect the accessible sample writings with the expected topic and length. The sample writings were collected both from the blog writing threads in the forum and the blogs of the blog writers. From 15 writings written by the first group of the study, there was one sent by a blog writer via email. The writings written by the second group were collected from English Department students of 
the University of Muhammadiyah Malang, an outstanding private university in the Province of East Java Indonesia. An English lecturer was invited to collaborate in deciding the group of students who were assigned to write English writings with the given topic and length. In this regard, the lecturer helped decide one class, from the classes at the English Department, that was ready to be assigned to write the English texts. From a group of students that belonged to the same class, 15 writings were selected as the pieces to be analyzed based on the criteria given i.e. topic and length.

The writing pieces gathered from both groups were analyzed manually based on Halliday and Hasan's (1976) framework due to its comprehensiveness. The coding scheme can be seen in Table 1.

Table 1. The coding scheme for the analysis of the use of cohesive devices

\begin{tabular}{|l|c|}
\hline \multicolumn{1}{|c|}{ Type of cohesion } & Coding \\
\hline 1. Reference & $\mathrm{R}$ \\
\hline 2. Substitution & $\mathrm{S}$ \\
\hline 3. Connectives & $\mathrm{C}$ \\
Additive & 1 \\
Adversative & 2 \\
Causal & 3 \\
Temporal & 4 \\
\hline 4. Lexical cohesion & $\mathrm{L}$ \\
Repetition (same item) & 1 \\
Synonym or near synonym (including hyponym) & 2 \\
Superordinates & 3 \\
Antonym & 4 \\
\hline 5. Ellipsis & $\mathrm{E}$ \\
\hline
\end{tabular}

(adapted from: Rahman, 2013)

The coding scheme was the guideline to analyze the cohesive devices used in the writings. When a cohesive tie was found, it was categorized into one of the categories listed in the table.

The analysis continued to investigate the appropriateness of the use of cohesive devices. In this case, the analysis was carried out through the investigation of (1) errors in the use of cohesive devices that led to grammatical issues and (2) unnecessary use of cohesive devices that potentially led to boredom and ineffective sentences.

\section{Discussion}

Totally, 30 writings that were analyzed; 15 pieces were written by blog writers while the other 15 were written by English department students. The length of the texts written by the blog writers was ranging from 350 words to 526 words. For the writings written by the second group of the subjects, the length of the writings was ranging from 285 to 537 words. To start the analysis, the writings were read first to gain the comprehension of what the blog writers wrote and each sentence in the texts was numbered to provide the ease for the analysis. 


\section{Cohesive Devices Used by Indonesian Blog Writers}

The results of the analysis showed that lexical cohesion and reference were used most frequently by the blog writers followed by connectives. The blog writers used substitution very rarely while the ellipsis was found only once in a writing. The following table shows the cohesive devices used by the blog writers.

Table 2. Cohesive devices used in English blog contents written by Indonesian blog writers

\begin{tabular}{|l|l|l|}
\hline \multicolumn{1}{|c|}{ Types of Cohesive Devices } & \multicolumn{1}{c|}{ Frequency } & \multicolumn{1}{c|}{ Percentage (\%) } \\
\hline Lexical Cohesion & $968 \quad$ & $47.60 \%$ \\
\hline Reference & 738 & $37 \%$ \\
\hline Connective & 300 & $14.70 \%$ \\
\hline Substitution & 21 & $1 \%$ \\
\hline Ellipsis & 1 & $0.04 \%$ \\
\hline Total & 2028 & $100 \%$ \\
\hline
\end{tabular}

As seen from the table above, the lexical cohesion occurred most frequently the blog writers' writings. From the total of 968 (47.60\%,) items, repetition was used most with 678 items found followed by 229 items of synonyms and hyponyms, 43 items of superordinate, and 18 items of antonyms.

Reference was also used very frequently by the first group of the study. Totally, 738 (37\%) items were found in the blog writers' writings. Interestingly, the definite article 'the' was used 420 times. This is actually the reason why the use of reference in the writings written by the blog writers appeared to be big in number. Halliday and Hasan (1976) listed the definite article into their framework which belongs to a subtype of reference.

Connectives were used less frequently by the blog writers with $300(14.70 \%)$ items found. Most of the connectives were additives with 194 items followed by 41 items of causal, 35 adversatives, and 30 temporal connectives.

As stated, the substitution was used very rarely by the blog writers. There were only $21(1 \%)$ items of substitution found in the blog writers' writings while the ellipsis was used only once in a text written by the blog writers.

\section{Cohesive Devices Used by English Department Students}

In terms of frequency, the cohesive devices used by English department students were similar with the cohesive devices used by the blog writers. Lexical cohesion and reference were used most frequently followed by connective and substitution. There was no ellipsis used by the students in their writings. The summary of the distribution of the cohesive devices used by the students can be seen in the following table.

Table 3. Cohesive devices used in English blog contents written by English department students

\begin{tabular}{|l|l|l|}
\hline \multicolumn{1}{|c|}{ Types of Cohesive Devices } & \multicolumn{1}{c|}{ Frequency } & Percentage (\%) \\
\hline Lexical Cohesion & 834 & $45.25 \%$ \\
\hline Reference & 669 & $36.33 \%$ \\
\hline Connective & 334 & $18.14 \%$ \\
\hline
\end{tabular}


ADJES Vol. 8 No 1, March 2021 p. 1-16

\begin{tabular}{|l|l|l|}
\hline Substitution & 4 & $0.21 \%$ \\
\hline Ellipsis & 0 & $0 \%$ \\
\hline Total & 1841 & $100 \%$ \\
\hline
\end{tabular}

The lexical cohesion was used most by the students with 834 (36.33\%) items in total. 616 of those were repetition while synonym and hyponym were used 164 times. Only 34 items of superordinate and 20 items of antonym were found in the writings written by the second group of the research subjects.

Reference was the second most frequently used with 669 (36.33\%) items. Similar with the references used by the blog writers, the definite article occurred 311 times.

Regarding the use of connectives, the students used this type more than the blog writers did. There were $334(18.14 \%)$ items found in their texts. Additives were used most with 230 items found followed by causal with 46 occurrences, 37 items of temporal, and 21 items of adversatives. It is obvious that the students relied on the use of this type much to build the relations of the elements within their writings.

For the next two types of cohesive devices, English department students used a few numbers of substitutions in their writings. Only $4(0.21 \%)$ items were found. In addition, no ellipsis was found in students' writings.

From the results of the analysis, it is obvious that the two groups of the study shared a similar pattern in using the cohesive devices in their writings. The lexical cohesion was the most frequently applied by both groups followed by reference and connective. Substitution was used rarely in both blog writers' and students' writings while ellipsis was found only once in a blog writing's English content. The summary of the cohesive devices used by blog writers and English department students can be seen in Figure 1.

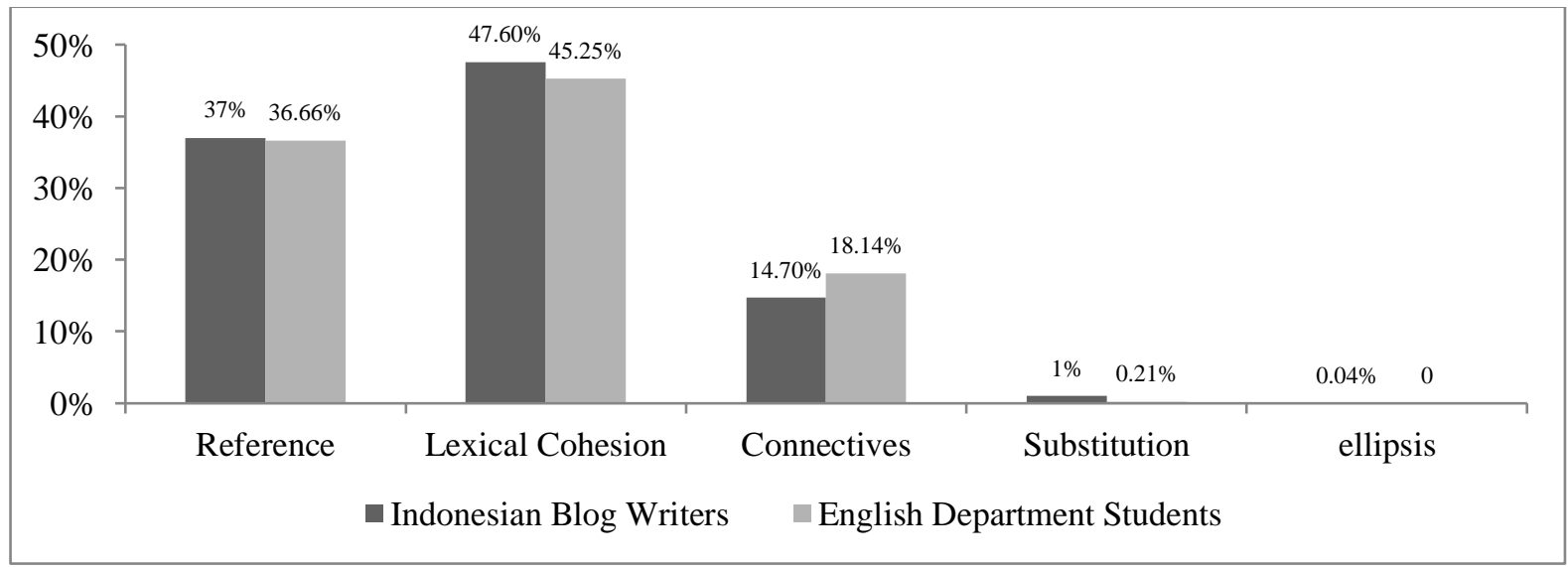

Figure 1. Cohesive devices used in English contents written by blog writers and English department students

As seen in Figure 1, both groups relied much on the use of lexical cohesion and repetition in constructing the cohesion of the texts they wrote. Interestingly, the students used connectives greater. The substitution was used rarely by both groups while the ellipsis was used only by a 
blog writer in his writing. The following figures show the summary of the use of lexical cohesion and connectives used by both Indonesian blog writers and English department students.

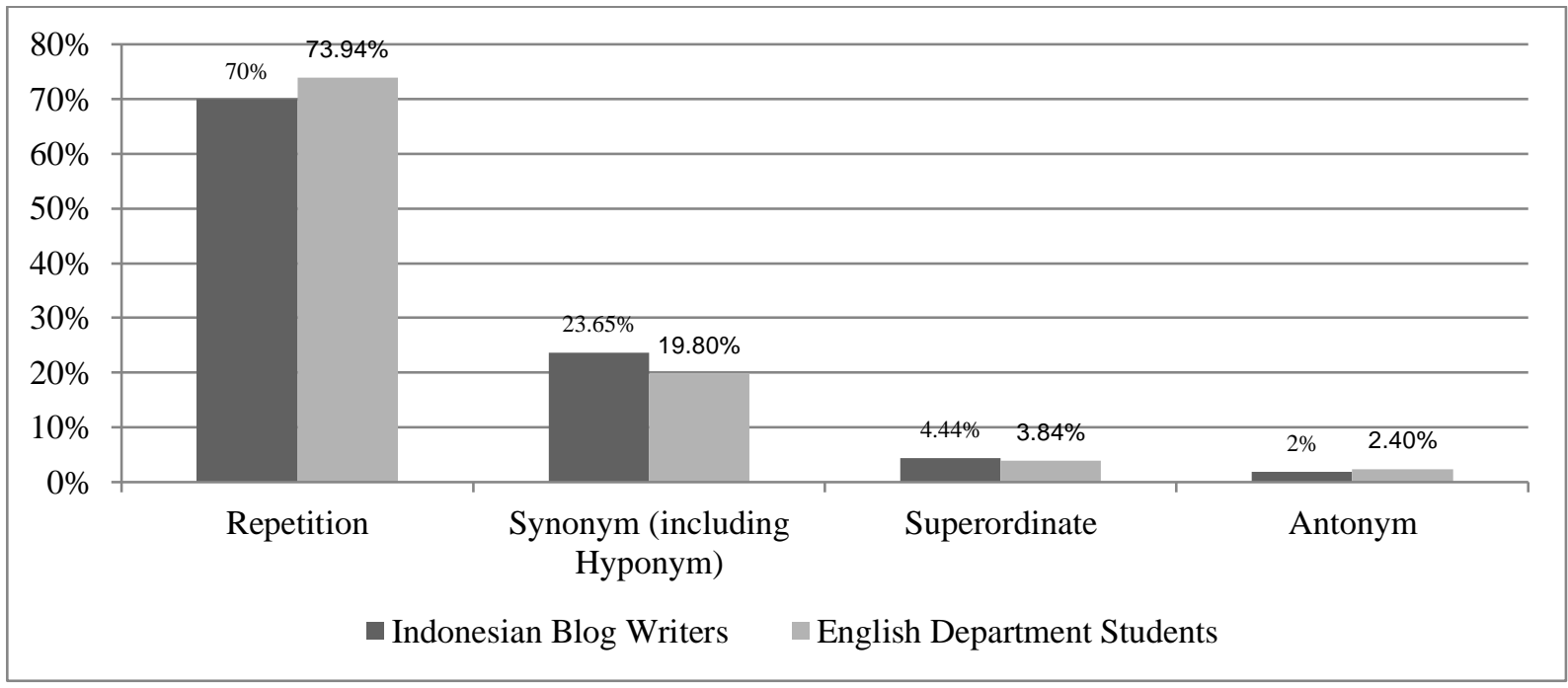

Figure 2. The distribution of the use of lexical cohesion in English blog contents written by Indonesian blog writers and English department Students

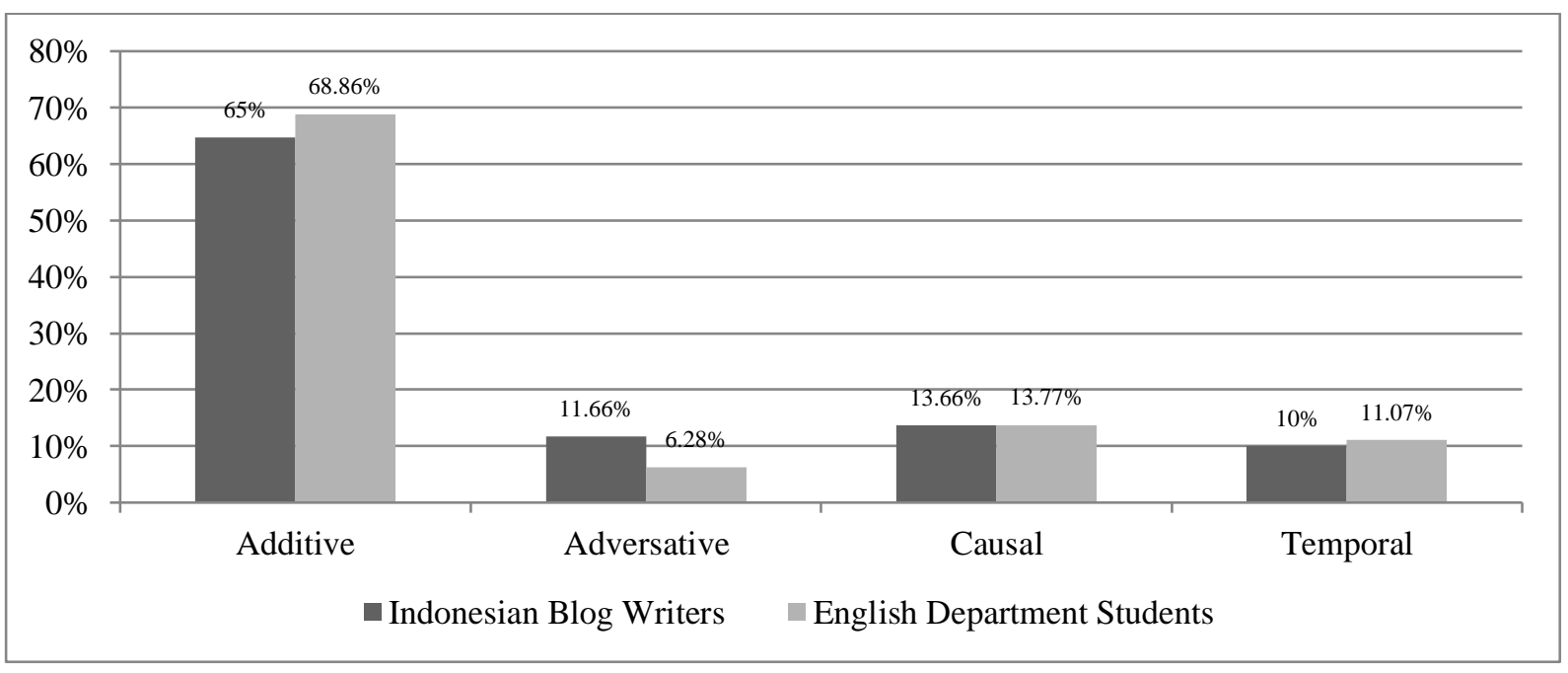

Figure 3. The distribution of the use of connective in English blog contents written by Indonesian blog writers and English department students

\section{The Difference of the Appropriateness of the Use of Cohesive Devices in English Blog \\ Contents Written by Blog Writers and English Department Students}

The investigation on the appropriateness of the use of cohesive device in English blog contents written by Indonesian blog writers and English department students was done by considering two aspects: grammatical errors that consisted of incorrect use of cohesive devices and inconsistent use of singular and plural forms of the vocabulary items found in the texts as well as any other issues that led to inappropriateness especially unnecessary repetitions that potentially led to boredom and ineffective sentence constructions. 
The result of the analysis showed that the texts written by both blog writers and English department students consisted numbers of inappropriateness. However, the blog writers performed better in using the cohesive devices than the students. There were 36 inappropriate items found in blog writers' writings while the English department students doubled the number with 73 improper cohesive items. From this point, the blog writers appeared to be more capable of using appropriate cohesive devices in their writings rather than the English department students.

The inappropriate use of cohesive devices that was found in blog writers' writings covered several aspects including errors in the use of definite article 'the', pronouns, and connectives, and unnecessary repetitions.

The inappropriate repetitions were found most with 13 items covering some aspects including inconsistent uses of the repetitions regarding the singular and plural forms, unnecessary repetitions that might lead to boredom and those that led to some grammatical issues. An example of the inconsistent use of repetition regarding the singular and plural forms is in "Country can the perfect dining room decorating ideas for those who like classic touch in their houses." In this case, the underlined phrase should be in singular form of 'dining room decorating idea' because it referred to a single concept being discussed in the text. Another case of inappropriate repetitions was the items that simply were not necessary to be included in the sentences like in, "Despite limited space many people find creative ways to improve on small yard spaces." In this case, the underlined word should be removed from the sentence because the repeated word had been represented by the same vocabulary item previously.

There were 9 items that could be considered as error in the use of connectives. Eight of those improper connectives were the use of 'however' and 'but' which were supposed to express direct contrast. Some of the blog writers inappropriately used the connectives within and between sentences that did not show contradictory relations. For example, a blog writer said, "Your ultimate goal is to open the closet without having the stuffs fall on you, however you may also organize in a way which..." The use of 'however' in the sentence was inappropriate because the sentence did not indicate any contradiction. Another issue was the misuse of a connective like in, "For example are white, monochromatic, blacks and grays." The connective 'For example' in the sentence functions as the subject. Therefore, it would be better if the writer revise the sentence to be "The examples are white, monochromatic, blacks and grays." which means that the connective is no longer exists.

The improper use of definite article followed next with 7 items found. For instance, in the following example, "When you have the small backyard, you can...." a blog writer used the definite 
article that referred to a piece of information that had not been stated before. In this case an article ' $a$ ' is more appropriate to be used.

Regarding the inappropriate use of reference, there were 5 items found covering two aspects: inconsistent and unclear referencing. The example of the first aspect is in, "For example are white, monochromatic, blacks and grays. It is able to raise the updated style and energetic feeling." In this case, the underlined reference should be in plural form because the item referred to different colors stated in the previous sentence. The unclear referencing was found in, "Yeah, this is also the first element in which you can make them." In the sentence, it is unclear to which 'them' referred.

As stated previously, there were 73 inappropriate items of cohesive devices found in the texts written by English department students i.e. the inappropriate use of references with 31 occurrences, the inappropriate repetitions with 15 items, the inappropriate definite articles with 14 times of occurrences, and the inappropriate conjunctions and connectives with 10 items. In addition, there were 2 items of substitution and 1 item of antonym found to be inappropriately used in the texts written by the English department students.

The inappropriate references occurred in different ways: unnecessary references, inconsistent use of singular and plural pronouns, and ineffective use of the items. The reference that is considered unnecessary to be used can be seen in, "There are many ways to keep our home beautiful and cozy, for example, several people said the house it could be looked beautiful if...." In the sentence above, it is obvious that ' $i t$ ' is not necessary and can be removed from the sentence. Regarding the inconsistent use of singular and plural references, the inappropriateness was found as in, "I like my wardrobe and my dresser because it has unique design." For the ineffective use, a problem occurred in, "It look wonderful and make someone who is coming there to take a rest for a view minutes there." The underlined reference is ineffective because the information that the student wanted to tell had been clear enough without the existence of the reference.

Dealing with the inappropriate definite articles used in the students' writings, there were 14 items found. Mostly, the inappropriate definite articles occurred as unnecessary ones because the items of information to which they referred had not been mentioned in the previous parts of the texts. For example, a student wrote, "Around there, there are the small miniature of chess...." even though there was no information regarding small miniature of chess somewhere before the sentence.

There were 15 inappropriate items of reference found in students' writings. Unnecessary repetitions were found in several sentences such as in, "Your bathroom should always clean the bathroom to get that organized." and "The kitchen is a place that has a primary function to provide food and cooking place." Clearly, the repeated phrase and word in those two sentences can be 
removed. Further, there were also items of repetitions that occurred in incorrect word classes or part of speech. This was found in some sentences like in, "As parents, we must ensure our children bathroom has proper safety décor. Because we do not need décor which is beautiful but it does not safety."

Going further to the inappropriate use of conjunctions and connectives, there were 10 inappropriate items found. In a sentence, a student stated, “...cleaning the house might be something that is difficult to do. However the host need to pay attention...." The underlined connective was inappropriately used by the student because the two sentences did not show any direct contrast. The similar problems also occurred in other texts written by different students like in, "So house is the one of comfortable place that people have and need. However it should stay beautiful and cozy to make more comfortable."

Besides the findings of the inappropriate use of cohesive devices above, it is also important to present the findings regarding the inappropriate use of substitution and antonym in the students' writings. There were two inappropriate substitutions found in the text as in "Wooden chair or floral sofa is the one of vintage decoration which indicates "that is vintage", wooden chair is my favourite thing that should have in my home." and "So house is the one of comfortable place that people have and need." It is clear that the substitutions in the two sentences are not needed. Regarding the inappropriate antonym, there was one item found to be improper. In "To have a clean bedroom is easy and actually not too difficult because if you have a good discipline.", the underlined antonym is obviously unnecessary because the information has been delivered clearly.

From the result of the analysis of the inappropriate use of cohesive devices in the texts written by the two groups of the subjects, it can be concluded that English department students faced more complex problems in writing English texts properly.

The research findings are in line with the results of some studies that were conducted previously by different researchers. Zoltan (2013) in his doctoral dissertation exploring the construct of cohesion in Euro examinations found that lexical cohesion was most frequently applied cohesive device followed by reference and conjunction. The ellipsis and substitution were used but rarely. Another study, Rahman (2013) who investigated the use of cohesive devices in descriptive writing by Omani student-teachers and English native speakers found that lexical cohesion was used most frequently by his three subjects of study followed by reference, connectives, substitutions and ellipsis. Chen (2008), who investigated the use of cohesive devices by analyzing 46 essays written by 23 EFL college students who enrolled in the Basic English Writing course at National Tsing Hua University also found that the lexical cohesion was the most frequently utilized followed by references and conjunctions. Similar results were also 
reported by different researchers stating that lexical cohesion was used most frequently (Chanyoo, 2018; Jaya \& Marto, 2019; Wang \& Zhang, 2019). Even though NaYoonHee (2011) found that reference was the most frequently used cohesive devices followed by lexical cohesion, conjunction, ellipsis, and substitution when investigating the cohesive devices used in CMC texts written by American and Korean EFL writers, it is safe to conclude that the findings of this study are similar with the previous ones respectively.

Both blog writers and English department students used repetitions of the same items most frequently followed by synonyms and hyponyms, super-ordinates, and antonyms. This corresponds to the findings of the previous studies (Chen, 2008; Zoltan, 2013; NaYoonHee, 2011; Rahman, 2013) especially regarding the great number of the use of repetitions. Dealing with the use of repetitions, the recent studies that specifically focused on the investigation of the use of lexical cohesion were in accordance with the findings of this research (Mahardika, 2015; Kafes, 2012; Mirzapour \& Ahmadi, 2011). It means that the use of the repetitions which appeared to be the most frequently used one among the other types of the lexical cohesion is a common phenomenon. Dealing with the use of synonyms and hyponyms, the finding is parallel to the findings of previous research (Chen, 2008; Mirzapour \& Ahmadi, 2011; NaYoonHee, 2011; Rahman, 2013). The fact that the blog writers used greater number of synonyms and hyponyms indicates that they had better repertoire of vocabulary.

It is interesting to discuss the repetitions of specific phrases used by blog writers in their writings which were related to their writing topics. Nine blog writers kept using specific phrases including 'Small backyard landscaping ideas', 'Backyard garden design', 'Stone kitchen backsplash ideas', 'Dining room decorating ideas', 'Bathroom paint colors', 'Professional home designer', 'Backsplash material', 'Home depot deck', and 'Home security tips' that are commonly called as keywords The purpose of the use of the keywords is to drive traffic to website from organic or natural search (Hubspot, 2014: 34), especially in Google search engine, in which website users enter search phrases that usually consist of two to five words (Tutorials Point, 2015: 10). In short, the repetitions of certain phrases found in the contents written by the blog writers were done because of a specific reason.

The results of the analysis also showed that references were used most frequently by both groups of the subjects followed by connectives, substitutions, and ellipsis. This corresponds to the recent data found in previous studies. Alarcon and Morales (2011) who focused on the investigation of the use of grammatical cohesion in students' argumentative essay found that the reference had the highest frequency (90.67\%) followed by conjunctions (9.08\%) and substitution $(0.25 \%)$ in 61 essays written by Filipino undergraduate students. In addition to the great number of definite articles used, Chen (2008) reported the similar phenomenon stating 
that the definite article is the second most frequently used reference covering about $24 \%$ from the total number of reference items used. Interestingly, Zoltán (2013) who found that the definite article is the most frequently applied reference stated that the phenomenon happened simply because Halliday and Hasan (1976) categorize this type under reference.

The third type that was used frequently by the blog writers and the English department students was the connectives. From the total number of connectives found, additives were used most frequently followed by causal, adversative and temporal. The finding is parallel to what Zoltan (2013) reported. An interesting fact regarding the use of connectives is that the students appeared to rely more on the use of this type. In addition to the other two types of cohesive devices, the substitution was used 21 times by the blog writers while the students used this type 4 times. There was one item of ellipsis found in a text written by a blog writer while the same type was not found in any of the students' writings.

From the discussion on the use of the cohesive devices in English blog contents written by Indonesian blog writers and English department students, it can be concluded that the findings that answer the first and second research problems are similar with the findings of some previous research.

The results of the appropriateness analysis showed that the blog writers performed much better both lexically and grammatically in their writings. It is true that there were 13 items of repetition inappropriately used by the blog writers and the big reason why this happened should be related the effort of the blog writers to optimize the keywords in their writings. However, still, this fact explains that they lack of both lexical and grammatical competence. Besides, today's trend in SEO suggests that the blog contents should be human readable so that overusing the keywords is no longer acceptable (see: Tutorials Point, 2015; Hubstpot, 2014; Clark, 2014).

In accordance with Mahardika's (2015) findings, the result of the analysis on the inappropriateness of the use of cohesive devices indicates that the students lack both lexical and grammatical ability of the English department students because of the less exposure to English. It is also explained in Rahman's (2013) study that the Omani student-teachers whose L1 is Arabic faced weaknesses in using various types of lexical cohesions compared to the native speakers of English because the natives had experienced using the language way longer than the non-natives. The blog writers are exposed to English written texts as they have to find and read various references before they start writing the blog contents. This indicates that the texts read by the blog writers are the resources from which they find new vocabulary items as well as the models of how to write like the native speakers of English. 


\section{Conclusion}

The present research shows that both of the blog writers and English department students shared the similar pattern in using the cohesive devices in their writings. The lexical cohesion appeared to be the most frequently applied followed by the reference in both groups. The next was the connective while the substitution was used very rarely. However, there was an item of ellipsis in a blog writer's writing and none in the students'. Interestingly, the recent findings from the previous research showed the similar patterns. The similar patterns of using cohesive devices are probably related to coherence; a very essential aspect to facilitate easy reading.

The analysis on the appropriateness of cohesive devices used, that blog writers were more appropriate in using the cohesive devices than the students did. This indicates that the blog writers were better in their writing performance both grammatically and lexically. Further, it is essential to discuss here that the inappropriateness of the use of unnecessary repetitions made by some of the blog writers was caused by the effort they made to optimize the keywords of the articles. It means that they unnecessarily pushed themselves to use the repetitions since they wanted to attract more visitors to visit the websites where the contents were posted. However, even though this technique was known to be effective in getting the expected traffics, today's trend in SEO suggests that using too many keywords in the blog contents is no longer acceptable.

The students should be taught how to effectively and efficiently use the cohesive devices in their writings. This information is beneficial for the educators and curriculum developers in English language teaching area especially in the Indonesian context.

Next, the inappropriate use of the cohesive devices found in the writings written by the blog writers and English department students implied that they still face problems both lexically and grammatically. An important implication regarding the better performance shown by the blog writers is that they could benefit from their reading activities before writing the blog contents. This demonstrates that they got the proper models as well as the source of new information especially regarding the vocabulary. Therefore, inviting and motivating the students to read much more English texts, especially written by native speakers, will lead to better performance.

The last, it was stated in the first chapter that the blog writing is a relatively new field that is wide enough to be explored. It means future research is still needed to understand this area much better. For instance, the investigation on how their educational background influences their performance as blog writers can be an interesting topic to study. Investigating their routine as blog writers through observation and interview can also be chosen to open a better and deeper insight into blog writing as a relatively new phenomenon that is closely related to English language teaching and learning especially in Indonesian context. 


\section{References}

Alarcon, J. B., \& Morales, K. N. S. (2011). Grammatical cohesion in students' argumentative essay. Journal of English and Literature, 2(5), 114-127.

Ary, D., Jacobs, L.C., Sorensen, C., \& Razavieh, A. (2002). Introduction to research in education (8th Edition). Belmont, CA: Wadsworth.

Castro, C. D. (2004). Cohesion and the social construction of meaning in the essays of Filipino college Students writing in L2 English. Asia Pacific Education Review, 5(2), 215-225. https://doi.org/10.1007/bf03024959

Chanyoo, N. (2018). Cohesive devices and academic writing quality of thai undergraduate students. Journal of Language Teaching and Research, 9(5), 994-1001. https://doi.org/http://dx.doi.org/10.17507/jltr.0905.13

Chen, J. (2008) . An investigation of EFL students' use of cohesive devices. Thesis: National Tsing Hua University, 93- 107.

Clark, B. (2014). How to create compelling content that ranks well in search engines. Retrieved from: http://scribecontent.com/downloads/How-to-Create-Compelling-Content.pdf

Fraenkel, J.R. \& Wallen, N.E. (2006). How to design and evaluate research in education (6 ${ }^{\text {th }}$ Edition). New York: McGraw-Hill.

Google - Company - Our history in depth. Retrieved from: http://www.google.com/about/company/history/

Google. (2014). Search engine optimization starter guide. Retrieved from: https://support.google.com/webmasters/answer/7451184?hl=en

Halliday, M.A.K., \& Hasan, R. (1976). Cohesion in English. New York: Longman

Hubspot. (2014). Introduction to search engine optimization. Getting started with SEO to achieve business goals. Retrieved from: https://www.hubspot.com/hs-fs/hub/53/file-13221845pdf/docs/ebooks/introduction-to-seo-ebook.pdf

Jaya, \& Marto, H. (2019). Lexical cohesion in background of research used in undergraduate thesis: A case study in Madako University. 3rd English Language and Literature International Conference (ELLiC), 343-348. https://jurnal.unimus.ac.id/index.php/ELLIC

Kafes, H. (2012). Lexical cohesion: An issue only in the foreign language? English Language Teaching, 5(3), 83-94. https://doi.org/10.5539/elt.v5n3p83

Mahardika, R. (2015). Comparing Lexical richness and lexical cohesion of descriptive essays written by students with different exposures to English. Unpublished S2 Thesis. Malang: State University of Malang. 
Mirzapour, F., \& Ahmadi, M. (2011). Study on lexical cohesion in English and Persian research articles (A comparative study). English Language Teaching, 4(4), 245-253. https://doi.org/10.5539/elt.v4n4p245

NaYoonHee. (2011). Cohesive Devices in CMC texts produced by American and Korean EFL $\begin{array}{llll}\text { writers. } & \text { Linguistic } & \text { Research, } & \text { 743-771), }\end{array}$ https://doi.org/10.17250/khisli.28.3.201112.014

Nindya, M. A., \& Widiati, U. (2020). Cohesive devices in argumentative essays by Indonesian EFL learners. Journal on English as a Foreign Language, 10(2), 337-358. https://doi.org/https://doi.org/10.23971/jefl.v10i2.1949

Othman, A. K. A. (2019). Investigation of grammatical cohesive devices errors made by Saudi EFL students in written paragraphs: A case study of the University of Tabuk, Saudi Arabia. European Scientific Journal, 15(2), 1-10. https://doi.org/10.19044/esj.2019.v15n2p1

Prijambodo, V.L. (2009). The learning experience in EFL writing of an Indonesian writer: A case study on Budi Darma. Unpublished Dissertation. Malang: State University of Malang.

Rahman, Z. A. A. A. (2013). The use of cohesive devices in descriptive writing by Omani studentteachers. SAGE Open, 3(4), 1-10. https://doi.org/10.1177/2158244013506715

Saville-Troike, M. (2006). Introducing second language acquisition. Cambridge: Cambridge University Press.

Tanskanen, S. (2006). Collaborating towards coherence. Amsterdam: John Benjamins

Trisnaningrum, Y., Alek, \& Hidayat, D. N. (2019). Discourse analysis of grammatical cohesion devices in college students' academic essays writing. IJEE (Indonesian Journal of English Education), 6(1), 79-90. https://doi.org/http://doi.org/10.15408/ijee.v6i1.12502

Tutorials Point. (2015). SEO search engine optimization. Retrieved from: http://www.tutorialspoint.com/seo/seo_tutorial.pdf

Wang, J., \& Zhang, Y. (2019). Lexical cohesion in research articles. Linguistics and Literature Studies, 7(1), 1-12. https://doi.org/10.13189/lls.2019.070101

Warna, D., Wijaya, B., Sartika, E., \& Riznanda, W. A. (2019). Cohesive devices used in argumentative essays of undergraduate EFL students in Indonesia. English Franca : Academic Journal of English Language and Education, 3(2), 125-147.

Webmaster Tool Help - Google-friendly sites. Retrieved from: https://support.google.com/webmasters/answer/40349?hl=en\&ref_topic=2370419

Zoltán, L. (2013). Cohesion and writing quality: Exploring the construct of cohesion in Euro examinations. Doctoral Dissertation: University of Pécs. Retrieved from: http://nydi.btk.pte.hu/sites/nydi.btk.pte.hu/files/pdf/LukacsiZoltan2013.pdf 